\title{
Chapter 4 \\ Sociological Perspectives Across Individual \\ Experiences, Social Structures, \\ and Representations
}

\section{A Three-Level Literature Review}

Surrogacy generates questions about the impact it has on social relationships and institutions, on shared values, as well as the meanings that life events have within society. More than any other phenomena, those inherent to the existence of life itself, therefore of procreation and death, affect the same idea we have of humanity and raise questions that go beyond the analysis of social coexistence or the culture of a specific social community. I think that the spread of a new way of coming into the world brings with its implications of a much deeper and broader than the implications of the spread of a practice that exclusively concerns already existing subjects. This special relevance, in my opinion, should call for a measured approach in formulating interpretations of the phenomenon, forming opinions, and proposing policies to regulate it.

Although other phenomena can provide useful interpretative keys to mitigate the disorientation that causes an unprecedented practice such as surrogacy, there is a need to be cautious in making analogies that would lead to forgetting the peculiarities of the object of analysis, those characteristics that make it different from all other similar phenomena. It is certainly correct and interesting to read surrogacy in the light of forms of commercialization of the human body or forms of externalization of care to which society has become accustomed over time; however, if we fall into the error of forgetting its specificities, we will lose the opportunity to intercept some implications or to foresee reactions other than those generated by known phenomena. For example, it would be overly simplistic to think given that society has become accustomed to taking care of children of a few months old in a nursery, then also the custody of a pregnancy to a surrogacy agency will follow the same course: in the second phenomenon of externalization, family configurations and the origins of the human being are shaken to their foundations. On a rhetorical communicative level, it can be effective to compare surrogacy to adoption or care work to connote it of "normality" and "goodness", or on the contrary to interpret it as a form 
of slavery or female exploitation similar to prostitution so as to convince the public opinion to consider it as something deplorable. On the contrary, on a level of sociological analysis, phenomena that are different, for the subjects involved, contexts, and methods, must remain distinct.

Scholars from around the world, particularly anthropologists and sociologists who study assisted reproductive technologies and kinship, have long been contributing to the understanding of surrogacy and its social implications: this effort began when surrogacy was still practiced in its traditional form, and has continued with increasing attention over the past 15 years, following the parallel expansion of the gestational form and its transnational market. Although most of the studies deal with the United States and India, along with the spread of customers and markets in other countries, the interest of scholars has also diversified, thus contributing to the knowledge of the specificities of the phenomenon in Ukraine, Thailand, Israel, Canada, France, Italy, Spain, Mexico, Nigeria, Japan, Kazakhstan, and China. Both theoretical papers have been produced that explore concepts such as donating, agency, exploitation, commodification, maternity, parenting, as well as empirical studies, among which various ethnographies with surrogates and aspiring parents, but also with professionals in the sector, as well as studies of speech and representation in the media, analysis of the communication proposed by agencies and clinics, and discussions about policies and legal frameworks.

In the following pages I will provide an overview of the main themes dealt with in this large amount of literature, organizing it into three levels of analysis: individual experience (motivations of intended parents and surrogates), social structure (inequalities, commodification, and motherhood), and representations (media and feminism). I have used this subdivision into levels to bring order to a treatment that is very often contaminated by a dialectic inspired by the modalities of activism, where the goal is the imposition or defence of personal views on the theme and the need for one or the other policy (in this case, the need to abolish or legalize).

For example, one of the most common objections raised to the framing of surrogacy as a form of commodification of women and children or the exploitation of less well-off women is that this interpretation is merely "theoretical", or that it comes from the privileged professors and feminists, tending to a paternalistic attitude indifferent to the needs of less wealthy women that precludes them an opportunity for empowerment. In support of this objection, the testimonies of the surrogates gathered from many ethnographic studies are discussed, revealing how the directly interested self-narrate a satisfying experience without the perception of exploitation. The error of this objection is precisely that of confusing different levels of analysis which instead sociological analysis must strive to keep distinct, in order to be able to see the relationships, the superimpositions, and therefore to distinguish the empirical social reality from the ideal visions. Specifically, the two levels of personal experience (collected by the ethnographer) and the social structure are confused in this objection, where in the first, data are presented that speak of personal satisfaction and in the second, the development of procreation according to principles and practices is described specific to the market: they are not mutually exclusive aspects but constitute two coexisting dimensions of the same phenomenon. The fact that the rhetoric of 
giving a gift is found in the narratives of the surrogates to describe the lived experience in a positive way does not cancel the fact that the system in which this practice is carried out is oriented towards profit and organizes relations as commercial exchanges.

Similarly, the fact that surrogates do not self-represent themselves as "mothers" of the children they give birth to (Berend, 2012) is not sufficient to establish that in the present society, motherhood is no longer defined by childbirth, as it always has been, and is defined mainly by the intention. The same mistake is also made by confusing the representation level with that of structure. For example, the representation of surrogacy in the media as a win-win practice coexists with literature reporting strong inequalities between the parties, and these inequalities cannot be forgotten when wanting to understand how this new procreative practice affects the distribution of roles between men and women of different social status.

\section{The Individual Experience: The Motivations for Participating in Surrogacy}

One of the questions that keep social scientists busy is "why do some people take part in surrogacy arrangements?". From the studies that answered the question by directly asking aspiring parents or observing their behaviour, we learn that surrogacy is often a last resort, the only chance to have a child after a decision-making process in which other ways were also evaluated.

For the 7 Greek women interviewed by Zaira Papaligoura et al. (2015), surrogacy was preferred to adoption since the latter does neither allow to know the genetic heritage of the child nor keep the couple's infertility unknown, which in Greece weighs heavily, especially on male virility. For the 42 English couples studied by Fiona MacCallum et al. (2003), surrogacy was chosen after a long period of infertility, failed attempts with IVF, or as the only way for the man to have a biological child when the partner does not have uterus. In both studies, the decision to rely on surrogacy was a shared decision between the man and the woman.

Martin Smietana (2018) confirms that also for gay couples (his study is with 37 European and American homosexual men, who had a surrogate child in the United States) the choice of surrogacy is made only in the last stages of their reproductive consciousness and decision process. In a first phase, some aspiration of parenthood was developed, while in a second phase, the various possible ways to have a child were considered. For some, becoming parents had always been a latent possibility, but it only became relevant at a certain point in life. For others, the awareness of wanting a child had always been present. Some felt they had to give up on becoming fathers due to being gay, and only later realized that parenthood was a viable option for them. Once having decided to become parents, the search for the means to realize the project begins: which technique to choose between adoption, co-parenting, and surrogacy; having a home and financial stability; finding the money to pay for 
adoption or surrogacy. More than half of the Smietana interviewees considered adoption first, which was subsequently rejected due to the requirements, age, and medical history of the children. The choice of surrogacy is preceded by a search for information on the Internet, readings, comparison with other gay couples, and considerations on the ethical implications (especially for Europeans from countries where surrogacy is illegal). Only later is contact made with surrogacy agencies, for example, through fertility fairs or the web.

Understanding the motivations of the aspiring parents is not as much problematic as understanding the reasons why women are available to engage in a surrogacy transaction. The desire for a child, which is the basis of the intended parents' motivation to turn to this system of procreation, is culturally legitimate and in the public debate, it is not questioned with other possible interpretations. On the contrary, the voluntary and routine removal of the child from the parturient violates the image of the mother and the woman-foetus bond and approval or disapproval in public discourse of surrogacy is played on the different interpretations that are given to the role of the surrogate woman: an independent social agent who embraces a new opportunity of revenues, a victim of globalized social and gender inequality system, a commodified body, a strong and altruistic woman, etc. "Why do some women lend themselves to acting as surrogates?" is a crucial question for sociologists and anthropologists working on the issue (Berend, 2012). The most obvious answer, the need for money, is questioned or at least not considered a sufficient and exhaustive answer: what other reasons are there? Are women acting under pressure or are they completely free to choose based on comprehensive information? Can altruism and willingness to give a gift be two sufficient reasons in the absence of economic compensation? The answers to these questions are often sought through interviews with the directly interested parties, but Helene Ragoné, who is a pioneer of this type of study, warns about the reliability of the narratives as a data upon which to base the understanding of the motivations of the surrogates: a real understanding of their decision-making process cannot rely solely on their narratives as they are often "described as a scripted manner, reflective of culturally accepted ideas about reproduction, motherhood, and family and reinforced by the programs" (Ragoné, 1994, p. 52).

Understanding how deeply the interviewees are convinced of the words with which they explain their experience should be part of a psychological analysis that is not my responsibility, but I still consider useful to look at these narratives in the right perspective in the light of the mechanism that Arlie Hochschild (1983), on the basis of Goffman's theory of social interaction, calls emotional labour: "the management of a feeling to create a publicly observable facial and bodily display; emotional labour is sold for a wage and therefore has exchange value" (Hochschild, 1983, p. 7). According to Hochschild in the profession we put in place a "deep acting": we try to feel or not feel in a given way, based on what is expected of us to appear professional; this mechanism also occurs in personal and intimate relationships. Hochschild notes that the same mechanism is at work in the surrogates she interviewed in India: "they did the emotional labour needed to avoid a sense of loss 
and grief, working on their feelings to protect their sense of self as a caring mother in a world of everything for sale" (Hochschild, 2015, p. 46).

Ragoné's observation is also relevant in the studies of other colleagues, where there is a certain similarity between the interviewees' narratives and those proposed by the agencies or clinics, towards which the surrogates are in a subordinate relationship, as well as a certain concern of the surrogates not to be misjudged. The theme most used in the construction of a morally just image of oneself is that of giving a gift, combined with the devaluation of the economic motivation, or the altruistic representation of this same motivation when the money received is used for the good of the family. It is now worth considering in the main studies on the motivations of surrogates, how this rhetoric is articulated, gradually discovering other elements of the individual experience of these unprecedented social subjects.

Ragoné in 1994 published the book Surrogate Motherhood. Conception in the Heart, based on interviews with traditional surrogates in the United States; Ragoné subsequently expanded the study by also interviewing gestational-type surrogates and she noted how in the narratives of the latter, the concept of giving a gift is less present, while the surrogates who also supply their eggs emphasize it (Guerzoni, 2020). The surrogates interviewed by Ragoné emphasize the concept that surrogacy is a women's job, an opportunity to help infertile couples, a vocation or calling. They interpret their decision as an informed choice, and do not point out the class inequality in the relationships that are established with the intended parents. They appreciate being spoilt by them, for example, by being taken for dinner once a month by them. Some even admit that they are happy when pregnant because they feel healthier and prouder in this state and some feel there is a reason to be fatter. Their commitments increase between medical visits, meetings with intended parents, even in other cities, participation in support groups, and social events organized by agencies: they feel they have an important and noble commitment legally established by a contract, which justifies their temporary withdrawal of dedication to their families without the risk of passing for insensitive women who sacrifice traditionally female care roles for a career.

The surrogates interviewed in this study deny that their main motivation is money, money that in most cases they use not for themselves but to raise their family's standard of living. Ragoné links the devaluation of the importance of money to the rhetoric used by recruiting agencies: giving the gift of life to others is a message that has proven effective in finding women willing to become surrogates, since it allows them to use their procreative function in a commercial context without however betraying the socially shared principle in the West that children are priceless (Zelizer, 1994).

Similar to Ragoné, April Hovav (2019), studying the surrogacy industry in Mexico between 2014 and 2017, discovered that a representation of surrogacy as giving a gift is simultaneously used by agencies, surrogates, and intended parents to make the process more morally acceptable. According to Hovav, agencies exploit the widespread perception that giving a gift and altruism are antithetical to market logic, as if the two dimensions cannot coexist in the same phenomenon. This dichotomy is used to convince potential customers that the service is morally 
palatable and "disciplining surrogates to create a docile and compliant labour force" (Hovav, 2019, p. 3). Would-be surrogates in Mexico, generally working-class mestizos, who demonstrate that they are driven by pure economic necessity, are either not recruited or reoriented towards a more favourable attitude to being recruited: agencies want to prevent women from negotiating their compensation or asking for more money from clients. At the same time, the intended parents, who in Mexico for the most part are gay couples from high-income countries, try to preserve their morality by stressing that the surrogates they use are not poor and do not do it for money.

Amrita Pande (2014), who carried out an ethnography at one of the India's leading surrogacy clinics, argued that explaining willingness to have children for others through motivations other than money is a disciplining device: recruiters, often community-respected midwives, use the sense of guilt of mothers who are unable to feed their children. While convincing them to participate in the surrogacy programme with the prospect of a profit, once hired if they dare ask for more money, they are accused of being business-oriented like prostitutes: amoral figures from which the surrogates, in the recruitment phase, are invited to distinguish themselves, reassured by the fact that with surrogacy there is no contact with the man's body. According to Pande, through this double rhetoric of money, women are invited, on the one hand, to perceive themselves as good mothers (therefore dedicated to the well-being of the child), on the other, as good workers (who give a service in exchange for compensation).

This last representation, that of the worker, does not fit perfectly with the surrogates interviewed by Corinna Sabrina Guerzoni (2020) in the United States, who do not consider surrogacy a job, but rather a full-time task to help someone: they argue that if their business were a job, then the salary should be much higher than $\$$ 25,000 ; the money they receive is perceived not as a salary but as a reward for the physical and emotional commitment of the pregnancy and the expenses incurred (babysitting for their children, fuel to go to visits, work permits, etc.). In this study, as in the others cited, there is a devaluation of money by the surrogates, who instead prefer to motivate their activity as a form of helping other people.

The same mechanism also emerges from Heather Jacobson's study with surrogates in Texas and California (Jacobson, 2016): profit is not indicated by the interviewees as their main motivation, but constitutes an important extra that allows them to contribute to their family's financial plans, take a vacation, or save something for their children's future education. They live the experience as a job that requires them to make a constant commitment, physical and mental, in making decisions about the smallest behaviours to adopt so that the baby is born healthy. Jacobson highlights the pleasure that her interviewees say they receive from pregnancy: the experience of being pregnant satisfies them but they do not want any more children and for this reason, surrogacy seems to be the perfect job for these women. However, they feel guilty for being happy in this business as well as for the sacrifices husbands and children face during their pregnancy for others: according to Jacobson, through using compensation for their family, they find self-justification. 
The awareness that pregnancy has a certain impact on their families emerges clearly from the narratives gathered by Elizabeth Ziff (2017) in a particular type of surrogate, women married to men who work in the US military. In the narratives collected by Ziff, the choice to become a surrogate is described through the concepts of sacrifice and duty that characterize their role as wives in the military community: the meaning of their pregnancy is to make a difference in the lives of others, to contribute to the income of the family, to feel useful while their husbands are on a deployment, and gain recognition for their role (Ziff, 2017; Kessler, 2009). They recognize the daily and constant commitment, the physical and mental discipline, and the risks they face, and they are aware that pregnancy, with all its unpredictability, requires being put at the top of the priorities of the family unit, accustomed instead to moulding itself on the work needs of the male head of the house: if it is usually the army that is put first, during the surrogacy, it is the wife's needs that come first of all ("military first" becomes "surrogacy first"). This interpretation allows them to feel they acquire greater power and emancipation than the traditional division of roles. According to Ziff's estimates, military wives are 15-20\% of American substitutes: such a large proportion is explained by the difficulty these women have in finding a stable job due to the continuous transfer of their husbands (the unemployment rate is three times higher than other women) (Ziff, 2017). Furthermore, this group of women is particularly attractive to agencies since army medical insurance also covers surrogacy pregnancies.

One common thing in the studies presented so far is that by giving a child to others, these women feel strong, useful, and recognized. The Israeli surrogates interviewed by Elly Teman (2010) describe the moment of delivering the child as their most emotional moment of glory (trophy moment). Seeing parents being moved when they hug the newborn is also the recurring desire of surrogates observed by Zsuzsa Berend in their interactions on the largest moderated public surrogacy website in the United States. Delivery of the child is the final stage of surrogacy, which these women understand as a "purposeful, goal-oriented series of actions that is in many ways its own reward" (Berend, 2016, p. 12). The feeling of empowerment is invoked by a site moderator with these words: "You can do anything that you really want to do, there are no limits with smart and educated women" (Berend, 2016, p. 12). Similarly, Delphine Lance (2017) notes that the slogan "I make families, what is your superpower?" is a very popular slogan among American surrogate-heroines on the web.

The meaning of surrogacy as an act of giving in which the woman acquires centrality and importance is sometimes reinforced by a religious frame. Ragoné (1994) identified a representation of surrogates as donor angels, while Pande (2014) identifies a process of deification of the process of surrogacy: dormitory supervisors teach women to see surrogacy as a divinity or as a divine gift, which allows them to become richer and childless couples to have children. However, the emergence of this satisfying perception of oneself and the actions carried out depends on the cultivation throughout the process of a collaborative relationship with the intended parents, towards whom the surrogates tend to express a more emotional bond than that established with the child (Teman, 2010; Berend, 2016). 
The empowerment effect emerges from Sharmila Rudrappa's study (Rudrappa, 2015) in Indian clinics in Bangalore, where most of the surrogates were textile workers with a weekly wage of $\$ 100-150$. Accustomed to long and exhausting working days, exposed to frequent injuries, supervised and humiliated by their bosses, without the possibility of going to the bathroom, except during the 45 minutes lunch break, these women see in surrogacy a job that is not only more profitable but also less tiring and alienating, as well as more satisfying on an emotional level: they socialize in dormitories with other women and feel more satisfied in "producing" a child, making a couple happy and contributing to the well-being of their family, rather than a piece of clothing that after a few months will be forgotten.

Sheela Saravanan (2018), with an ethnography once again carried out in India, highlights how the feeling of reward and having been useful to one's own family is also accompanied by unpleasant feelings. For example, the surrogates told of a degrading experience in clinics, where they were subjected to the implantation of several embryos and subsequent miscarriages; in the clinics, they did not feel free, they were afraid to make any requests or ask for information, and their needs were ignored or treated with disdain. They were often worried about the family left at home as they spent their pregnancy in the clinic. They complained about a lack of transparency when they were not given a copy of the contract or did not fully understand it. They reported feeling used by the intended parents and disappointed for not having had more contact after handing over the child, who in some cases not only having given birth to but, if the parents were late, also fed, developing an even stronger bond than during the pregnancy. They suffered having to detach themselves from the child, even though they were aware that this was part of their obligation as surrogates.

Some important data emerged from these ethnographies. First of all, it was understood that the economic return is a decisive reward in the willingness of women to have children for others, both in the United States and India, countries that can be considered representative of two very different worlds due to their socioeconomic conditions and social position of women in which the surrogacy market has taken root. Nevertheless, the economic reward alone is not sufficient to decide to become a surrogate. It is strengthened through the perception of pregnancy as a pleasant experience and the altruistic sense that is attributed to participating in the process of filiation of others, people who alone without the help of a third woman would be deprived of happiness. The scarcity of opportunities for large earnings also plays its part in pushing women into this market. It also emerged that the surrogates are keen to present their business as morally acceptable and, given the social perception of the amorality of money, especially if linked to the use of the female body, they do so by emphasizing the use of profit for the well-being of the family and not just for themselves, thus devaluing the importance of money in their choice. It is also worth recalling how the devaluation of economic motivation mirrors the rhetoric of giving a gift used by the communication agencies to present their business as something ethical and not at all amoral. Furthermore, the self-represented experience is intertwined with the feeling of increased self-esteem in proving to be strong and selfless women, in having a role in the well-being of others, in receiving 
recognition from the family, and in becoming entrepreneurs by improving their standard of living. However, the experience of these women also involves great sacrifices, negotiations with their own feelings, and feelings of degradation that undermine their integrity: during the contract, they lose their autonomy and depend on the requests and wishes of others, who by the nature of the transaction, have priority over the well-being of the woman, who places herself at their service.

\section{The Social Structure: Inequalities and Stratified Reproduction}

A recurring theme in the literature on surrogacy is that of inequality, related to the three identity elements of gender, class, and race, as well as to their intersectionality, analysed both as a pervasive characteristic of the organization of the market and at the interpersonal level between the subjects directly involved in the transaction. It is common knowledge that surrogacy is supported and developed precisely by the existence of significant inequalities of economic availability and social class between the women who make their bodies available and those who get a child. This inequality is present both when the service is carried out within the same country and when the clients go abroad.

It is a fact that the users of the services are people with greater economic means than the service providers, who use the earnings to fulfil different types of needs or projects to improve the standard of living of their families. Without the "bioavailability" (Cohen, 2007) of local labour, the market would not spread. However, it is worth pointing out how agencies tend to prefer women who are not among the poorest: their health could be compromised by poor housing conditions, have a non-reassuring aspect for clients, be poorly nourished, and forced into this type of work due to poverty (Rudrappa, 2015). Rozée et al. (2019) even found that the social situation of 96 Indian surrogates tended to be better than that of the general population of women aged 20-34 in terms of education (half had received at least a secondary education), employment (half had been employed before surrogacy), and family income (above the poverty line). The scholars suppose that this result is due not only to the criteria and preferences of recruitment by medical doctors, but also to the fact that while in the early 2000s when the surrogacy industry started in India, surrogates were recruited by brokers (often formerly surrogates themselves or egg donors) through word of mouth, later agencies started to advertise in the press and television. They suggest that "women who have more autonomy and who are better integrated in social networks are more likely to have access to information and to clinics, and so to commit to surrogacy" (Rozée et al., 2019, p. 6).

Notwithstanding these findings, there is no doubt that richer women are not interested in this source of income, but those of the lower-middle working class, who at any moment, due to an unexpected event such as an illness, or a marriage, could end up in poverty are interested (Saravanan, 2018). 
On the other hand, the clients mostly belong to the upper-middle class: the difference in income, but also in education and opportunities, between the surrogates and clients is an evident constant. To use the words of Sharmila Rudrappa: "Even when individual clients are genuinely good human beings, feel deep gratitude, and adequately express their everlasting appreciation to their surrogate mothers, they cannot overcome the structural inequalities that exist between them" (Rudrappa, 2015 , p. 4). Rudrappa reads the transnational surrogacy market as "a classic case of stratified reproduction that results in unequal transactions because these are exchanges between already unequal social actors" (Rudrappa, 2015, p. 4).

The concept of stratified reproduction is often used in surrogacy studies (Saravanan, 2018; Pande, 2014; Harrison, 2016; Twine, 2015; Rudrappa, 2015): it is a term coined in 1986 by Shellee Colen (1995) to explain the "physical and social reproductive tasks are accomplished differentially according to inequalities that are based on hierarchies of class, race, ethnicity, gender, place in a global economy, and migration status and that are structured by social, economic, and political forces. The reproductive labour-physical, mental, and emotional —of bearing, raising and socializing children [...] is differentially experienced, valued, and rewarded according to inequalities of access to material and social resources in particular historical and cultural contexts. Stratified reproduction, particularly with the increasing commodification of reproductive labour, itself reproduces stratification by reflecting, reinforcing, and intensifying the inequalities on which it is based" (Colen, 1995, p. 78.).

Colen's concept was taken up by Ginsburg \& Rapp who exemplify it in this way: "power relations by which some categories or people are empowered to nurture and reproduce, while others are disempowered" (Ginsburg \& Rapp, 1995, p. 3). Harrison (2016) applies this concept in relation to the fact that in the United States the disproportion in the use of reproductive technologies between white and non-white population is significant: at 12.3 percent of the population, African Americans constitute 4.3 percent of users, and at 12.6 percent of the population; Hispanics make up 5.5 percent of recipients. Ryan (2009) notes that while the international agenda for reproductive health for developing countries emphasizes the goal of controlling population numbers and thus making methods of contraception accessible, in the Northern part of the world, the policies are to support the birth rate and therefore to regulate access to methods of reproduction to circumvent infertility. Similarly, the issue of infertility becomes marginal in female activism in the Global South where there is an urgent need to address the effect that government policies of procreative control are having on women's bodies and gender discrimination (e.g. sexual selection). In the South of the World, women have poor access to medically assisted procreation due to the high costs, also derived from the import of methods developed in the North, and the scarcity of public programmes to support fertility and reproductive health, a problem at the scale of priorities in the health and development agenda of governments in poor countries (Ryan, 2009). This creates the paradoxical situation in which the same women who do not have access to quality maternal and sexual health-care services enter the latest generation of clinics to have children for other people. 
Debora Spar (2006), France Winddance Twine (2015), and Laura Harrison (2016) apply Colen's concept to read surrogacy as the historical continuation of a culturally accepted breakdown of reproductive labour. For example, Spar refers to the Middle Ages when aristocratic mothers benefited from the help of nurses, who were poorer women. Twine (2015) recalls that black women in the United States have been deprived of procreative freedom for centuries since the descendants of Africans worked as slaves and produced children for the market, while the children of non-slaves did not have this market value. Twine (2015) specifies that although the surrogates now voluntarily enter the contract, unlike the slaves of the past, this decision takes place within a stratified system of inequalities. Harrison also argues that surrogacy reinforces the hierarchical differences built into the difference in race and the conception of race as a set of biological characteristics transmitted genetically: parents agree to entrust their foetus to a woman with a different skin colour because they believe that the quality and characteristics of their child are determined by the genetics of the gametes and not by the characteristics of the pregnant woman, in fact very rarely are the gametes selected from suppliers of different races. There are also cases of parents who are not willing to entrust their foetus to a surrogate of a different race and vice-versa some surrogates are not willing to work for couples of different races, as they would perceive the foetus as a stranger.

Sheela Saravanan explains the classism of the transnational market of surrogacy, which she defines as post-colonial, with the formula of one third of those who have (haves) against two thirds who do not (have nots) (Saravanan, 2018, p. 23): the former buy a service, the latter provide it. Looking specifically at India, Saravanan points out that in the case of complications during childbirth, the life of the surrogate is given less value and priority than that of the child, with the unwritten rule in light of a hierarchy of value that is attributed to the lives of the rich and the poor, to those of the citizens of the Global North and the South. Saravanan argues that the presence of a large, poor female population has been a fundamental element in the spread of surrogacy in India, not only due to a question of economic need but also because poverty is linked to low schooling and the persistence of traditional practices in which the woman depends on the expectations and decisions of other family members: this socio-cultural background sets the stage for the poor protection of the rights of Indian surrogates, which is an attractive factor for intentional parents. A courteous and submissive attitude is, among other things, a characteristic that agencies take into consideration when choosing surrogates: the more assertive ones are discarded.

Furthermore, the sociologist points out that there is not only a notable unequal economic and bargaining power between the surrogate and clients but also a clear difference in the treatment of Indian surrogates compared to those of countries where women have a greater emancipation. For example, according to the information reported by Saravanan (2018), if in the United States surrogates have access to support groups, legal assistance, health insurance, and maternity-related benefits, the same cannot be said for India, where they are often detained in dormitories, they are not asked to choose the couple to have a baby for, they do not have access to a copy 
on the contract, and they do not receive any compensation in the case of a miscarriage.

Pande (2014) links Colen's concept to the surrogate recruitment strategies put in place by Indian midwives, who encourage a certain type of women, those who cannot afford to support more children, to have children for others. They are also convinced through manipulation: for example, they are led to interpret their displeasure at having had miscarriages in the past as evidence that they were not destined to become mothers again.

Gerrits (2016) confirms that there is a stratified reproduction mechanism also at work in the Ghanaian surrogacy market: the customers are Ghanaian citizens of the diaspora and other elites from African countries, the service providers are local women.

Finally, the concept of stratified reproduction also applies to access to surrogacy services by categories other than the infertile heterosexual couple: same-sex couples and singles are categories that are often prevented by law from using surrogates. This is due to the fact that categories other than the heterosexual couple have long been considered traditionally unsuitable for raising children, an idea upon which today there is less consensus: the initial regulation of assisted reproduction was made on the basis of dominant ideas of infertility understood as the impossibility of having a child despite unprotected sexual relations between a male and a female (Smietana et al., 2018).

A fundamental fact emerges from this overview: the surrogacy market feeds on structural inequalities, especially in income opportunities, and is practiced through unbalanced relationships, in which the surrogate is the least protected part, but is compensated economically for her availability.

\section{The Social Structure: Reification and the Market}

Surrogacy has been studied by many as yet another form of invasion of the logic of the market in social life, one of the various services offered by the infertility industry which in fact commodifies procreation through the attribution of economic value to parts of the body (conceived as raw materials) and experiences (services). In specialist literature, as well as in the discourses of social movements opposed to the practice, the concept of commodification is applied to the entire reproductive process, the woman's body, the child and life.

One of the reference studies on this interpretation is Clinical Labor Tissue Donors and Research Subjects in the Global Bioeconomy by Melinda Cooper and Catherine Waldby (2014). The Australian scholars consider medically assisted procreation as an expression of the contemporary global neoliberal capitalism and highlight how the surrogates, as well as the suppliers of the eggs, do a paid job to carry out a productive process within their bodies: this involves the scanning of biological processes and body self-management to ensure product quality control. Women employed in the procreation industry (and men, as sperm suppliers) are not 
hired as the labour force but rather are compensated as suppliers of genetic resources. By signing the contract, the egg and pregnancy suppliers agree to lease their excess reproductive capacity, which gains value once it enters the global market. Cooper and Waldby (2014) highlight how the logic of the accumulation of genetic capital, through strategies and recruitment criteria, pursues a process of class reproduction: the egg suppliers are selected according to the most requested phenotype, height, body mass, absence of hereditary pathologies, and the level of education. The surrogates, on the other hand, are selected-not on the basis of the phenotype given that they do not transmit the genetic heritage- but on the basis of the state of health and the pregnancies already had.

The aforementioned Sharmila Rudrappa (2015) is inspired precisely by the concept of bio-economies treated by Cooper and Waldby, or economies "built from the latent value held in biological materials" and "frontier technology that involves a transformation of life forms such as biofuels and hybrid crops, for the purposes of profit", to define surrogacy as one of the various "markets in life": a market that "creates surplus value by harvesting marginal forms of vitality- the foetal, cadaverous, and extracted tissue, as well as bodies" (Rudrappa, 2015, pp. 8-9).

Another milestone book for framing surrogacy as a market is Baby Business by Debora Spar (2006): the Harvard Business School professor describes the infertility market as a business that produces "a good that is inherently good. It produces children, for people who want them" (Spar, 2006, p. 196). Spar presents four existing market models for other types of goods that could be taken as inspiration to also regulate the fertility market. The first option is to treat the "potential child" as a precious jewel: only those who can afford it will be able to have it and there will be no risk of too high a demand. The second option is that of prohibition, as with drugs: the effect would be the black market. The third is to adapt the rules adopted for human organs to children: they are distributed not on the basis of the availability of money but on the basis of the level of need, the waiting time, and the compatibility between donor and recipient. The fourth model is inspired by hip prostheses, considered a social good that the market could not distribute without excluding the poorest.

In this reading of surrogacy as a production process, there is clearly a commodification of the woman, reduced to one of her reproductive organs: the uterus is "technically and legally isolated as a component that can be contractually ordered, detached from the selfhood of the surrogate and repositioned in a production chain at the behest of the clinic and commissioning couple" (Cooper \& Waldby, 2014). An example of this conception of the (re)productive process is the expression "womb for rent", a terminology used by those who condemn surrogacy as a form of exploitation and commodification of women.

Along this line of thought, Maria De Koninck (2020) recently wrote the book Stolen Motherhood: Surrogacy and Made-to-Order Children, in which she highlights how wrong it is to think that pregnancy only affects a woman's uterus and that this is comparable to any other organ of the human body. The Canadian sociologist points out that the uterus, if extrapolated from the body, loses its usefulness and that 
alone, without the participation of the whole body of the woman, cannot make a foetus grow. De Koninck also emphasizes that the language of economics and that of technology, from which expressions such as carrier and third-party reproduction originate, separate pregnancy (reduced to gestation, a term used in the animal world) from the identity of the woman (a woman is pregnant) and from her status as a total experience that involves affectivity, the psyche, and transforms her person.

Similar considerations were also made by Janice Raymond as early as 1991 when the feminist and Emeritus Professor of studies on women and medical ethics published in the feminist journal $M s$, a harsh article in which she described surrogacy as "a system in which women are movable property, object of exchange, brokered by go-betweens mainly serving the buyer" and as the "procurement of women for breeding" (Raymond, 1991, p. 30). Before Raymond, the feminist Gena Corea (1985) in her The Mother Machine had warned about the danger that the segmentation into phases of the procreative process implemented in surrogacy could devalue the very concept of human procreation (even natural) by assimilating it to one of the many production processes subject to the division of work. The eco-feminist thinkers who refer to the thought of Corea see in this commodification of the uterus, an attack on woman's nature and her procreative potential, whose control has always been coveted by male power: biotechnologies intervene on the composition of being human, allow for the selecting of sex and produce the perfect child, eugenic operations justified by the ideology of the enslavement of nature and woman to man through technology (Corradi, 2017).

From the aforementioned Hochschild study (2015) with Indian surrogates, it is possible to see how that of the uterus-carrier is not only a representation formulated by scholars who analyse the practice from the outside, but also an image induced by the clinics in the same surrogates to facilitate their necessary detachment from foetuses and intended parents. The sociologist argues that this mode of social relationship, as well as self-representation of personal experience, is imposed by a business model to which women without earning opportunities must adapt, but whose purpose is the competitive positioning of the company/clinic in the assisted procreation market. According to Hochschild (2015), women, in order to cope with the scarcity of public services, due to the neoliberal model, embrace the culture of the free market by making the free choice to put their generative capacity up for sale.

\section{The Social Structure: Fragmentation of Motherhood and New Family Formations}

Biomedical technologies render it possible to make procreation independent from sexual intercourse and in this way open up to innumerable combinations of parenthood and filiation, introducing new statuses (for example, that of the surrogate) and modifying the characteristics of traditional statuses (for example, to become a father, it is not necessary to have had sexual intercourse with a woman). Parenthood has 
always been defined on the basis of the genetic link with the child or, in particular cases, with the social role (in the case of the adoption or recognition of a partner's child). With medically assisted procreation, in some cases the genetic criterion is privileged for the attribution of parenthood (in surrogacy), other times this is considered irrelevant with respect to the intention to be a parent and the bodily bond that is established in gestation (when the woman uses a donor) (Johnson, 2017).

In other words, medically assisted procreation transforms kinship from a fixed and natural system to a cultural product that can be composed as desired. Thompson (2005) analyses the phenomenon of doing kinship by describing how in fertility clinics, patients, doctors, sperm donors, egg donors, and surrogates take an active part in this process of configuring kinship: giving different meanings and relevance to substances that in the body are shared with the foetus, to the genes, to the "relational" stages such as conception and bearing, and to the "custodial" stages, in which embryos and gametes are taken care of, this leads to "the alignment of procreative intent and biological kinship" (Thompson, 2005, pp. 145-148). This process of re-signification is reflected on a structural level in the paradigm shift of filiation, from naturalistic to voluntary: parenting is increasingly understood, both at a legal and a social sensibility level, as a voluntary issue for which the source of parental status is the will of adults, even more than two, who participate in the procreation process (Nicolussi, 2018).

In gestational surrogacy, those who according to various criteria could be considered parents are as many as six: the surrogate, her partner, the egg donor, the intended mother, the intended father of intention, and the sperm donor. Unlike other forms of medically assisted procreation, surrogacy introduces an unprecedented change: if the mother has always been legally and socially the one who gives birth (criterion applied in the legal principle of mater semper certa est) and if this criterion is also maintained with heterologous fertilization, in gestational surrogacy, pregnancy and childbirth are experiences that no longer count for the attribution of this status (Jotkowitz, 2011). Moreover, with surrogacy, it is admitted that the social identity of some children, and adults of tomorrow, is that of people without a mother, for example, when the intended parents are two men. It is evident that these are profound transformations in the definition of mother, as well as in the social status of motherhood, points which literature often discusses.

Johnson (2015) underlines that motherhood is no longer an objective fact, but an open concept, subject to redefinition by multiple claim-makers, as well as a status that needs to be articulated, claimed, and debated to be recognized: Johnson uses the concept of "contingent maternities: forms of maternity established through carefully constructed arrangements that can potentially be challenged" (Johnson, 2015, p. 1361). In surrogacy, it is the intention followed by the initiation of the whole medical-legal process, as well as the contract and economic investment to attribute the status of mother. The genetic contribution is also added, which however may not be present in some surrogates, yet the status of mother is conferred to that of intention. On the other hand, nourishing and care during pregnancy, which in rare cases continue after childbirth with breastfeeding (Lance, 2017), do not confer the 
status of mother to the surrogate, who manifests at the beginning of the process the "non intention" to become one: the woman who gives birth is given the status of collaborator in procreation or carrier.

On the importance attributed to genetics in the conferral of parental status, the observation made by Riggs (2018) is interesting in relation to surrogacy for gay couples: the biological father minimizes the genetic link to affirm parental equality between him and the partner who does not provide the genetic heritage. In light of these parenting realities, it is worth considering whether motherhood could be male. Stacey (2006) states that gay fatherhood is interconnected with gender roles and as gay fathers intentionally and purposefully pursue nursing roles, overcoming various obstacles, this desire can best be understood as more like motherhood than heterosexual paternity. Equally in lesbian motherhood obtained through the pregnancy of an embryo formed with the partner's egg, the role of the latter is compared to that of man in heterosexual procreation (Thompson, 2005). These elaborations of meaning on the maternal figure in relation to being either male or female are part of the feminist reflections begun half a century ago on the emancipation of women from the patriarchal belief that nature assigns innate characteristics to the two sexes: in this constructivist conception, biomedical technology is hailed, both by some feminists (followers of Firestone, supporters of the artificial uterus) and transhumanists, as a tool to free women from the burden of motherhood and to concretize genderless mothering (Corradi, 2021).

From this discussion, it is evident that when motherhood is separated from pregnancy and childbirth, as well as from the woman, to be instead associated to intention, the semantic claims on it can be the most varied, just as the number of perceptions, the constructions of meaning and the interpretations of the personal experiences of the subjects who take part in the procreative process can be. Corradi (2021) warns of the confusion that can be generated when pretending to separate two dimensions of motherhood, childbearing and childrearing, without distinguishing the social level from the epistemological one: making this separation on the first level means admitting that the woman who gives birth wants to give away the child or sharing the caring role with a partner or another person; supporting a separation on an epistemological level, on the other hand, questions the identity of the human person with mind and body, not the roles we have as "social agents".

The fragmentation of the mother that generates enthusiasm among the intellectuals of the constructivist paradigm, however, generates many concerns in those who instead recognize in the female sexual identity, the only possible bodily basis for the experience of motherhood. The feminist philosopher Luisa Muraro (2016) defends the uniqueness of the relationship between mother and foetus, in which the sexual difference of every human being is constituted. According to Muraro, the mother can be replaceable, but the maternal relationship is not. In France, the philosopher Sylviane Agacinski (2019) reiterates that procreation, whether natural or artificial, needs the contribution of the two sexes, and is therefore indispensable from sexual difference. The aforementioned Canadian sociologist De Koninck (2020) points out that even if the experience of motherhood is made irrelevant, as a mere passage necessary to obtain an end, and as the man no longer needs to give a mother to his 
child, the woman however, is always needed to give birth, as long as surrogacy is not replaced by ectogenesis.

How much does surrogacy devalue the experience and social role of motherhood? To what extent does it free women from the social expectations of motherhood, and how much does it consolidate the normativity of the female status of mother, making it feasible even when, due to infertility, it would not be possible to achieve it? Similarly, how much does surrogacy represent an emancipation of women and men from the family institution and the social expectations of compulsory parenthood and how much does it reaffirm the centrality of the family, albeit with new forms, as an institution on which society organises itself and for through which the individual finds recognition?

In the aforementioned study on surrogacy in Israel, Teman (2010) argues that surrogacy is functional to the pro-natalist policies of the state based on the centrality of the family: in Israel, remaining childless is a non-socially accepted choice and motherhood is historically seen as a national mission of women, therefore surrogacy is a means, controlled by the state, to create families and carry out compulsory motherhood.

Lewis (2018, pp. 3-4) argues that surrogacy in itself is potentially revolutionary but this force is nullified by the capitalist way in which it is thought and practiced today, in line with the capitalist conception of childbearing more generally: "capitalist surrogacy becomes legible as a dynamic contradiction in itself, containing latent possibilities that are highly relevant to early Reproductive Justice militants' desire to abolish the nuclear family. When we refrain from casting it in a special realm apart from everyday reproduction, it becomes obvious that the grammar of commercial surrogacy is fundamentally premised on anti-polymaternalism. Cutting kinship into secure and sanitary sections, maintaining strict separation between participants' life-worlds rather than bridging them, private surrogacy clinicians assure commissioning parents that their surrogate's body will leave no trace upon its product, their baby". In her recent book Full Surrogacy Now (2019), Lewis invites to recognize pregnancy as productive work, to overcome the presumption that children belong to those with whom they are genetically linked, to build a system of collective kinship.

\section{The Representation Level: Public Discourse in the Media}

Some scholars have dealt with how surrogacy and its protagonists are represented in the mainstream press and media news (Due \& Riggs, 2010; Majumdar, 2014; Markens, 2007, 2012; Riggs \& Due, 2013), TV series (Gondouin, 2012), supplier sites of these services (Lozanski \& Shankar, 2019), a mix of these and other sources (Harrison, 2016), as well as in the legal (Birenbaum-Carmeli, 2007) and anthropological (Segalen, 2021) discourse. The purpose of these studies is to outline the public discourse on surrogacy by taking into consideration the meanings proposed and conveyed by several voices (discourse makers) through texts available to the 
public: within which frameworks is the phenomenon framed? What are the meanings and values attributed to it, the aspects emphasized and those silenced or minimized? What is the recurring rhetoric? What is the relationship between the representation of surrogacy and existing conceptions of family, motherhood, infertility, gender relations? Altruism, commodification, and choice are the recurring themes in the following review, themes that have already appeared both at the level of subjective experiences and that of social structure. I will specifically examine the main studies that focus on the representation proposed by the mass media.

Susan Markens' (2007) book Surrogate Motherhood and The Politics of Reproduction is a fundamental text for understanding how surrogacy was presented in the United States between the 1980s and 1990s when the transition from traditional to gestational surrogacy occurred. Markens takes into consideration three horror stories that have marked the American debate and analyses the mainstream press for its primary role in determining the agenda setting and thus orienting policies.

The first in the late 1980s involved a long custody dispute in New Jersey between a couple of intended parents, the Sterns, of whom only the father was the child's genetic parent, and a woman, Mary Beth Whitehead, surrogate, and biological mother of Baby M, the disputed child. The mainstream press analysed by Markens framed surrogacy as baby selling: a "crass commerce", a phenomenon with economic motivations that contrasted with the dominant perception of procreation and motherhood, and that had to be stopped. The result was a State law that prohibited surrogacy.

The second horror story analysed by Markens takes place in the 1990s in California: the dispute for the custody of the child delivered by Ms. Johnson, this time gestational surrogate, for the Calverts, the intended parents. In this case, the maternal link between the pregnant woman and the foetus, emphasized in the case of Baby M, was diminished as the pregnant woman was not the biological mother, while the intended parents by virtue of their genetic link were seen as the only real parents. Surrogacy, says Markens, in this second case was no longer represented as baby selling but as a service that a stranger, motivated by her economic needs and for this reason to be doubted, carried out for a couple to be considered parents in all respects. The message asserted was that surrogacy was not to be stopped since it provided an answer to the pain of infertility; however, it had to be regulated, for example, by preventing an accurate selection of surrogates according to their motivations, and therefore adapting the laws to the advances of medical science. California, subsequently this case, adopted the most surrogacy-friendly legislative framework in the United States.

The dichotomy between good and bad surrogates established on the basis of altruistic or economic motives is also noted by Harrison. Analysing print media, television, documentary film, websites, and databases of surrogacy and egg donation agencies, and court records and other American legal documents, Harrison observes that the public discourse on surrogacy is filled with the same rhetoric of giving a gift that in the first part of this review permeated the narratives of the surrogates. In the media, surrogacy is mainly represented as a relationship of solidarity (women helping women), which is "good" as long as it is not motivated by money, but by 
altruism, sacrifice, and empathy, as normative characteristics of the good mother. Like Markens, Harrison also argues that the frame of women helping women removes from the imaginary the idea that surrogacy can be a form of commodification that takes place in a context of imbalance of power between surrogate and intended parents.

In contrast, Due and Riggs (2010), who analysed the current affairs show 60 Minutes aired in 2009 in Australia, which told the story of a couple of gay men from Melbourne who had twins in India, highlight the frame of commodification. According to the authors, the surrogates are represented as "objects available for commodification by those living in the overdeveloped west" (p. 1). The objectification of the surrogate rests on the perception of the uterus as an empty space, chosen by the intended parents to give them a healthy child, and on the presumption that the absence of a genetic link with the foetus, also made evident by the diversity of race, also constitutes an absence of relationship. Pregnancy is downgraded to a "business arrangement" and the right or desire of the intended parents to have a biological child is privileged to that of the women; the latter, as the authors note, to contribute to the formation of the family of others must sacrifice their own families, as well as run the risk of not being able to have other pregnancies for themselves.

Is surrogacy represented differently when it happens in the United States and when it happens in India? This was asked by Markens who in a subsequent work analysed three media accounts from 2008 (The New York Times and Newsweek), discovering that the internationalization of the sector responds with two competing frames, exploitation/inequality versus opportunity/choice. In the wake of concern about the advent of global capitalism, surrogacy in India was presented in the American media as an opportunity to make money, offered by would-be American parents and that women in poor countries could choose to take in a context of elevated global inequality. Conversely, the compassionate attitude of surrogates who help infertile people to build a family was emphasized when presenting surrogacy in the United States, while the economic nature of their motives was downplayed. Markens concludes that supporting surrogacy is constructed by dissociating reproductive labour from commodification through the rhetoric of female altruism and family-building when the transaction takes place in the United States and is enriched with a rhetoric of empowerment and choice to justify the economic motivations of the Indian surrogates.

Gondouin (2012) has analysed two Swedish TV series and found that surrogacy is represented as a win-win economic transaction between benefactor-couples from the Global North and surrogates in poor countries who are depicted as strong women choosing freely to gestate for others: the frame of aid and giving a gift is intertwined with the economic frame. Even the aforementioned Riggs and Due in analysing the Australian mainstream press (Riggs \& Due, 2013), find that intended parents in India are represented as benefactors: this frame mitigates their vulnerability, which is given by the dependence on a third woman to realize the desire for a child and the impossibility during pregnancy to affect the well-being of the foetus, kept in the womb of this woman in a far-off place. These benefactors are represented as "agentic 
citizens" of the global market, who cope with their desperation for not being able to have a child by resorting to surrogacy abroad as their only and last solution.

This neoliberal framework is also confirmed by Hvidtfeldt (2016) in the analysis of two documentaries: in Google Baby and Made in India, intended parents pursue through surrogacy in India a project of liberation from the unsatisfied desire to have a child; they are represented as legitimate customers as well as legitimate parents thanks to the genetic link with the child, while the surrogates are represented as entrepreneurs of themselves.

\section{The Representation Level: Feminism}

In this last part of the literature review I will examine three publications that discuss the different approaches of feminism to the topic of surrogacy. I chose these three texts, from the wide range of publications on the subject (Belliotti, 1988; Roman, 2012; Lewis, 2016; Lieber, 1992 among others), because I believe they offer a clear contribution to the systematization of the variety and diversity of feminist positions.

Before starting, I would like to first clarify that feminism is both a theoretical perspective and a social political movement; that scientific elaboration, dissemination, and activism often coexist in the professional lives of feminist authors; that many concepts initially developed within feminist reflections have become so popular that they have become part of culture, a lens through which women and men interpret their private relationships, and values that a society must embrace in order to consider itself democratic or civil; that social phenomena affecting women are mostly studied from a perspective that adheres to this feminist "culture", and admittedly or not to feminist theory (Browder, 2015; Young, 1999; Touraine, 2009). These dynamics are also present in the production of knowledge, popular and scientific, on surrogacy which therefore includes publications authored by women who are both academic and militant, studies that explicitly use feminist theories, texts developed starting from feminist principles that have become shared culture and values. I have not found it useful to make these distinctions in the literature review developed so far, which instead I have chosen to organize around recurring themes; one of which is feminism and that I will examine in this last part. In these paragraphs, four studies will be reported that show what the main arguments, perspectives, and representations used by feminists in the production of knowledge on surrogacy are. This review allows me to summarize the current literature to which my study can be included and which the following chapters will discuss: the contribution of feminism to the public discourse on surrogacy and to the debate on its regulatory or prohibition policies in the United States, Mexico, and Italy. In reconstructing the different positions that divide feminism in these countries and the evolution of mobilization, the recurring themes in the literature examined in the first two levels will also return, bearing witness to a permeability between the level of scientific production and that of public discourse, as well as activism. 
The first text I propose as a starting point for trying to sort out the variety of feminist perspectives on surrogacy, and to classify the different positions in relation to some of the trends of feminism, is the book by Dion Farquhar (1996). In The Other Machine, Farquhar identifies the main perspectives on reproductive technologies in the American and Anglo-American debate: the liberal perspective, present in popular and medical discourse, represents reproductive technologies as tools that allow desperate infertile couples to have a child; the fundamentalist one, in which the secular, religious, and feminist soul coexist, represents reproductive technologies, respectively, as a commercialization of life, a serious danger for the traditional family, and a source of oppression of women.

Farquhar makes an initial macro distinction between liberal equality feminism and radical feminism: the first denies the existence of characteristics inscribed in sexual difference and prefers to speak of similarity between genders by assuming masculinist standards as neutral, standards to which women are invited to approach in order to emancipate themselves; the second, on the other hand, exalts female biological differences as superior to male ones and proposes a redemption of women, and which, recognizing their oppressed status, can fight to create a worldview centred on the nature of women.

Farquhar then dwells on radical feminism and identifies two different positions in it: the anti-natalist position which "extols the virtues of refusing maternity and its corollary mandate, altruism, on the grounds of women's selfinterest" (Farquhar, 1996, p. 100); and the pro-natalist one that idealizes the experience of motherhood (natural, universal, and ahistorical) as an experience in which the woman realizes herself and expresses everything that is feminine, in harmony with nature. Both eco-feminists and feminists of difference belong to radical feminism and both oppose reproductive technologies since they see them as harmful to the health and integrity of women, tools of patriarchy to expropriate the woman of control over her body and her reproductive capacity, which according to these feminists has always been envied and coveted by males: women are removed from nature, the source of femininity, to be transformed by technology into machines. The spokesperson for this position is the Feminist International Network of Resistance to Reproductive and Genetic Engineering (FINNRAGE) founded among others by Gena Corea, Renate Klein, and Janice Raymond.

According to Farquhar, both the anti-natalist and pro-natalist positions assimilate motherhood to pregnancy and understand it as "overdetermined", be it "unequivocally bad" (or a desire induced by false consciousness, a source of oppression, and imposed sacrifice) or "unequivocally good" (emotionally satisfying, source of special power). Anti-natalists reject reproductive technologies (but not technologies designed to prevent anti-conceptional and abortive maternity) because they transfer "the control of women from individual men in marriage to "technodocs" within institutional science and technology". The pro-natalists, on the other hand, "oppose technological intervention into reproduction on the grounds that it fragments unitary maternity, marginalizes "women's knowledge", and interferes in natural maternal processes" (Farquhar, 1996, p. 104). The radical feminist discourse and that of religious fundamentalism or pro-life meet according to Farquhar as both contribute 
to the conception of female identity as universally maternal: "aborting women are configured in the same way as infertile women; they share the (male) cultural status of absent nurturant maternity" (p. 116).

In the chapter dedicated to surrogacy, Farquhar traces the main opposition arguments invoked by feminists between the 1980s and the early 1990s: surrogacy commercialises motherhood in a class-based way by allowing some more disadvantaged women to become breeders for others who are more privileged; surrogacy violates the natural bond between mother and child; surrogacy re-proposes the model of exploitation of women in brothels with the difference that the sale of the reproductive function is not viewed with prejudice since it does not involve sexual intercourse; surrogacy reinforces the male claim to paternity and weakens the female claim to motherhood.

The second text I want to quote is an article by Beth Rushing and Suzanne Onorato (2003). The authors describe the different positions on reproductive technologies in three main feminist currents, namely the liberal, radical, and socialist, and link these positions to the theories adopted by each stream to explain the causes of female oppression and the function of procreation. Liberal feminists focus on women's free procreative choice regardless of the social context and would like to ensure equal access to reproductive technologies for all women. This position derives from the fact that, as Farquhar has already pointed out, liberals identify the origin of inequality in the perpetuation of fixed gender roles, which instead should be reformed through the integration of women into the social mainstream. A reasoning similar to that on prostitution is proposed on surrogacy: the woman must be completely free to choose if and how to use her body (even on the market).

Radical feminists, both those who see motherhood as an obstacle to emancipation and those who celebrate female reproductive capacity, point out that these technologies are a danger of oppression because they are developed in a system dominated by men and hatred of women. The goal of the radicals is the subversion of the patriarchal system of oppression of women which is also maintained through male control over procreation: technologies could also help in this process of liberation but instead they are an obstacle since they are designed according to the patriarchal logic of separating the woman from the procreative experience and from the child. On surrogacy, radical feminists think it is a way to make some women into baby machines and others to make them irrelevant.

Socialist feminists trace the causes of female oppression, not in biological difference, nor even solely in male class advantage, but in the way of organizing the social relations of the production of commodities and the (re)production of people: their goal is to transform the distribution of the division of labour in both spheres by basing the new system on the sharing of responsibilities between men and women. Socialists argue that reproductive technologies maintain the state of female oppression because they contribute to the alienation of women from their reproductive work, are used capitalistically for profit, and are developed by men. Socialists oppose surrogacy as a form of commodification of women and children: they see in the expression surrogate uterus, the signs of the alienation that this practice entails. 
The third text presented for its contribution to the systematization of the feminist discourse on surrogacy is an article written by the sociologist of law Vanessa Munro (2001). Munro traces the following main arguments in support of surrogacy, which she too agrees in attributing mostly to the liberal current of feminism. The first is the defence of contractual autonomy: the autonomy of women in deciding to become a surrogate must be defended and any prohibition is seen as an attack on female selfdetermination; on the other hand, there is the contractual autonomy of those who want to enter into a contract with the surrogate and the prohibition is seen as a violation of procreative freedom. Women must be free to enter the market as men have always done: selling their procreative services allows them to pursue paths of empowerment. Finally, there is the argument of the child as the first beneficiary of surrogacy, as a greatly desired child. On the other hand, the main arguments used by the opposing front mostly focus on the consequences on the surrogate: surrogacy involves the exploitation of the poorest or most vulnerable women; moreover, it involves an alienation that is not comparable to other forms of manual labour as it implies the emotional experience of the woman as a woman (Pateman, 1988).

All three texts criticize the feminist perspective on surrogacy since it helps to create a polarized vision not only of the practice itself but more broadly of the categories dear to feminism itself (and to sociological criticism): on the figure of the mother, who Farquar stresses cannot be read adequately with the use of the binaries of good and bad or of the victim and monster; on procreation, which Rushing and Onorato recall as being both a private individual issue and a social and public one. Munro, on the other hand, blames feminism, both for and against, for focusing only on ethical issues and the benefits or dangers to the individuals involved in surrogacy, forgetting to consider the social implications that surrogacy has for all pregnant women (in particular contributing to the dichotomous ideology of the maternalfoetal relationship in which the woman and the foetus are understood as two distinct subjects or "patients" with conflicting interests). According to Munro, a feminist debate placed in this way not attentive to the wider community of women, falls short of the vocation of the feminist theory itself, summarized in the words of Alison Jaggar as follows: "first, to articulate moral critiques of action and practices that perpetuate women's subordination; second, to prescribe morally justifiable ways of revisiting such actions and practices; and third, to envision morally desirable alternatives that will promote women's emancipation" (Jaggar, 1992, p. 361).

Finally, I would like recall a recent work published by Emma Maniere (2017) in the Babies for Sale anthology edited by Miranda Davies, as it provides a very clear and useful classification of the two main approaches (abolitionist and reformist) to the policies proposed by feminist scholars. I will adopt this classification in the analysis of feminist positions in the three case studies. The abolitionists, more numerous in Baby M's time than now, invoke a total ban of a practice that commodifies the woman's body and children, reconfirms the class and gender hierarchies, and subjects procreation to the logic of the market and alienated labour. The reformists, on the other hand, propose a regulation that can contain ethical pitfalls and protect the parties better: usually based on the testimonies collected in the field (of which abolitionist analyses are lacking), they question the agency, 
autonomy and choice in the decision of women to become a surrogate, bearing in mind the daily living conditions of these women (for example, the working conditions and the risks to which they are subjected, for which surrogacy represents the lesser of the two evils). The defect of the reform proposals is, according to Maniere, that of not proposing concrete and particular policy solutions. Maniere identifies a third approach, less common among feminist scholars: the libertarian one, supported by those who consider the current rules sufficient and trust the free market to facilitate reproductive choice. The author notes that there are many common concerns between abolitionists and reformists, most notably the concern that surrogacy involves the exploitation of the woman and an inversion of her agency. Maniere invites both majority factions to consider the issue of the best interest of the children born via surrogacy, currently overshadowed by a priority concern for the condition of women.

\section{References}

Agacinski, S. (2019). L'Homme désincarné. Du corps charnel au corps fabriqué. Gallimard.

Belliotti, R. A. (1988). Marxism, feminism, and surrogate motherhood. Social Theory and Practice, 3, 389-417.

Berend, Z. (2012). The romance of surrogacy. Sociological Forum, 27(4), 913-936.

Berend, Z. (2016). The online world of surrogacy. Berghahn Books.

Birenbaum-Carmeli, D. (2007). Contested surrogacy and the gender order: An Israeli case study. Journal of Middle East Women's Studies, 3, 21-44.

Browder, S. E. (2015). Subverted. How I helped the sexual revolution hijack the women's movement. Ignatius Press.

Cohen, L. (2007). Operability, bioavailability, and exception. In A. Ong \& S. J. Collier (Eds.), Global assemblages. Technology, politics, and ethics as anthropological problems (pp. 79-90). Blackwell.

Colen, S. (1995). "Like a mother to them". Stratified reproduction and West Indian childcare workers and employers in New York. In F. D. Ginsburg \& R. Rapp (Eds.), Conceiving the new world order (pp. 387-406). University of California Press.

Cooper, M., \& Waldby, C. (2014). Clinical labor: Tissue donors and research. Duke University Press.

Corea, G. (1985). The mother machine. Reproductive technologies from artificial insemination to artificial wombs. Harper \& Row.

Corradi, L. (2017). Nel ventre di un'altra. Una critica femminista delle tecnologie riproduttive. Castelvecchi.

Corradi, C. (2021). Motherhood and the contradictions of feminism: Appraising claims towards emancipation in the perspective of surrogacy. Current Sociology, 69(2), 158-175.

De Koninck, M. (2020). Stolen motherhood. Surrogacy and made-to-order children (Kindle ed.). Baraka Books.

Due, C., \& Riggs, D. W. (2010). Gay men, race privilege and surrogacy in India. Outskirts Online Journal, 22. https://www.outskirts.arts.uwa.edu.au/volumes/volume-22/riggs

Farquhar, D. (1996). The other machine: Discourse and reproductive technologies. Routledge.

Gerrits, T. (2016). Assisted reproductive technologies in Ghana: Transnational undertakings, local practices and 'more affordable' IVF. Reproductive Biomedicine \& Society Online, 2, 32-38.

Ginsburg, F. D., \& Rapp, R. (Eds.). (1995). Conceiving the new world order. University of California Press. 
Gondouin, J. (2012). Adoption, surrogacy and Swedish exceptionalism. Critical Race and Whiteness Studies, 8(2), 1-20.

Guerzoni, C. S. (2020). Gift narratives of US surrogates. Italian Sociological Review, 10(3), 561-577.

Harrison, L. (2016). Brown bodies, white babies. The politics of cross-racial surrogacy. NYU Press.

Hochschild, A. R. (1983). The managed heart: Commercialization of human feeling. The Regents of the University of California.

Hochschild, A. R. (2015). The surrogate's womb. Gender, rovné př́ležitosti, výzkum, 16(2), 42-52.

Hovav, A. (2019). Producing moral palatability in the Mexican surrogacy market. Gender \& Society, 20(10), 1-23.

Hvidtfeldt, K. (2016). "All one needs is a credit card.”: Transnational surrogacy in India on weblogs and in documentaries. In V. G. Rozée \& S. Unisa (Eds.), Assisted reproductive technologies in the global south and north: Issues, challenges and the future (pp. 137-148). Routledge.

Jacobson, H. (2016). Labor of love. Gestational surrogacy and the work of making babies. Rutgers University Press.

Jaggar, A. (1992). Feminist ethics. In L. Becker \& C. Becker (Eds.), Encyclopaedia of ethics (pp. 361-370). Garland Press.

Johnson, K. M. (2015). Single, straight, wants kids: Media framing of single, heterosexual fatherhood via assisted reproduction. Journal of Gender Studies, 26(4), 387-405.

Johnson, K. M. (2017). Contingent maternities? Maternal claims-making in third party reproduction. Sociology of Health and Illness, 39(8), 1349-1364.

Jotkowitz, A. (2011). Surrogate motherhood revisited: Maternal identity from a Jewish perspective. Journal of Religion and Health, 50, 835-840.

Kessler, B. (2009). Recruiting wombs: Surrogates as the new security moms. Women's Studies Quarterly, 37(1/2), 167-182.

Lance, D. (2017). Mettre a distance la maternité. La gestation pour autrui en Ukraine et aux EtatsUnis. Ethnologie Française, 167(3), 409-420.

Lewis, S. (2016). Defending intimacy against what? Limits of antisurrogacy feminisms. Signs, 43 (1), 97-125.

Lewis, S. (2018). International solidarity in reproductive justice: Surrogacy and gender inclusive polymaternalism. Gender, Place \& Culture, 25(2), 207-227.

Lieber, K. B. (1992). Selling the womb: Can the feminist critique of surrogacy be answered? Indiana Law Journal, 68(1), 205-232.

Lozanski, K., \& Shankar, I. (2019). Surrogates as risk or surrogates at risk? The contradictory constitution of surrogates' bodies in transnational surrogacy. Social Theory \& Health, 17, 4056.

MacCallum, F., Lycett, E., Murray, C., Jadva, V., \& Golombok, S. (2003). Surrogacy: The experience of commissioning couples. Human Reproduction, 18(6), 1334-1342.

Majumdar, A. (2014). The rhetoric of the womb. The representation of surrogacy in India's popular mass media. In S. Dasgupta \& S. Das Dasgupta (Eds.), Globalization and transnational surrogacy in India (pp. 107-123). Lexington Books.

Maniere, E. (2017). Mapping feminist views on surrogacy. In M. Davies (Ed.), Babies for sale? (pp. 312-327). Zed.

Markens, S. (2007). Surrogate motherhood and the politics of reproduction. University of California Press.

Markens, S. (2012). The global reproductive health market: U.S. media framings and public discourses about transnational surrogacy. Social Science \& Medicine, 74(11), 1745-1753.

Munro, V. E. (2001). Surrogacy and the construction of the maternal-foetal relationship: The feminist dilemma examined. Res Publica, 7(1), 13-37.

Muraro, L. (2016). L'anima del corpo. Contro l'utero in affitto. La Scuola.

Nicolussi, A. (2018). Famiglia e biodiritto civile, le parole del diritto. Scritti in onore di Carlo Castronovo. Jovene. 
Pande, A. (2014). Wombs in labor. Columbia University Press.

Papaligoura, Z., Papadatou, D., \& Bellali, T. (2015). Surrogacy: The experience of Greek commissioning women. Women and Birth, 28(4), e110-e118.

Pateman, C. (1988). The sexual contract. Polity Press.

Ragoné, H. (1994). Surrogate motherhood. Conception in the heart. Westview press.

Raymond, J. (1991). Women as wombs. Ms, 1(6), 28-41.

Riggs, D. W. (2018). Making matter matter: Meanings accorded to genetic material among Australian gay men. Symposium: Making Families - Transnational Surrogacy, Queer Kinship, and Reproductive Justice, 7, 150-157.

Riggs, D., \& Due, C. (2013). Representations of reproductive citizenship and vulnerability in media reports of offshore surrogacy. Citizenship Studies, 17(8), 956-969.

Roman, D. (2012). La gestation pour autrui, un débat féministe? Travail, Genre et Societé, 2(28), 191-197.

Rozée, V., Unisa, S., \& de La Rochebrochard, E. (2019). Sociodemographic characteristics of 96 Indian surrogates: Are they disadvantaged compared with the general population? PLoS One, 14 (3), e0214097.

Rudrappa, S. (2015). Discounted life: The price of global surrogacy in India. NYU press.

Rushing, B., \& Onorato, S. (2003). Controlling the means of reproduction: Feminist theories and reproductive technologies. Humanity and Society, 27(3), 393-413.

Ryan, M. A. (2009). The introduction of assisted reproductive technologies in the «developing world»: A test case for evolving methodologies in feminist bioethics. Signs, 34(4), 805-825.

Saravanan, S. (2018). A transnational feminist view on surrogacy. Springer.

Segalen, M. (2021). Deconstructing social anthropology discourses in their support of surrogacy: The case of France. Current Sociology, 69(2), 286-299.

Smietana, M. (2018). Procreative consciousness in a global market: Gay men's paths to surrogacy in the USA. Symposium: Making families - Transnational Surrogacy, Queer Kinship, and Reproductive Justice, 7, 101-111.

Smietana, M., Thompson, C., \& Twine, F. W. (2018). Making and breaking families - Reading queer reproductions, stratified reproduction and reproductive justice together. Reproductive Biomedicine \& Society Online, 7, 112-130.

Spar, D. L. (2006). The baby business: How money, science, and politics drive the commerce of conception. Harvard Business School Press.

Stacey, J. (2006). Gay parenthood and the decline of paternity as we knew it. Sexualities, 9, 27-55.

Teman, E. (2010). Birthing a mother the surrogate body and the pregnant self. University of California Press.

Thompson, C. (2005). Making parents. The ontological choreography of reproductive technologies. MIT Press.

Touraine, A. (2009). Il mondo è delle donne. Il Saggiatore.

Twine, F. W. (2015). Outsourcing the womb. Race, class and gestational surrogacy in a global market. Routledge.

Young, C. (1999). Ceasefire! Why women and men must join forces to achieve true equality. Free Press.

Zelizer, V. (1994). Pricing the priceless child: The changing social value of children. Princeton University Press.

Ziff, E. (2017). "The mommy deployment": Military spouses and surrogacy in the United States. Sociological Forum, 32(2), 406-425. 
Open Access This chapter is licensed under the terms of the Creative Commons Attribution 4.0 International License (http://creativecommons.org/licenses/by/4.0/), which permits use, sharing, adaptation, distribution and reproduction in any medium or format, as long as you give appropriate credit to the original author(s) and the source, provide a link to the Creative Commons license and indicate if changes were made.

The images or other third party material in this chapter are included in the chapter's Creative Commons license, unless indicated otherwise in a credit line to the material. If material is not included in the chapter's Creative Commons license and your intended use is not permitted by statutory regulation or exceeds the permitted use, you will need to obtain permission directly from the copyright holder. 